\title{
Ventilator-Associated Events 5 Years Later
}

Almost 5 years have elapsed since the United States Centers for Disease Control and Prevention (CDC) replaced their ventilator-associated pneumonia (VAP) surveillance definitions with ventilator-associated event (VAE) definitions. The CDC shifted to VAE definitions in response to a litany of concerns about traditional VAP definitions, including their complexity, subjectivity, burden upon surveyors, lack of comparability between institutions, narrow focus, and limited association with adverse outcomes. ${ }^{1}$ VAE definitions were therefore created to increase the objectivity and reproducibility of surveillance, facilitate automation, and broaden the focus of safety surveillance to encompass any event severe enough to require a sustained increase in ventilator support (including noninfectious events). ${ }^{2}$ During calendar year 2014 (the latest year for which data are available), $>1,800$ United States hospitals reported VAE rates to CDC. ${ }^{3}$

In this month's issue of Respiratory CARE, Kobayashi et $\mathrm{al}^{4}$ provide useful confirmation of many key aspects of VAE epidemiology. They retrospectively analyzed 407 consecutive adults ventilated for $\geq 4 \mathrm{~d}$ within the general ICU of an academic hospital in Tokyo. The study team assessed incidence, overlap, and attributable mortality for VAEs and traditionally defined VAPs. They found that VAEs were present in almost 3 times as many subjects as traditionally defined VAP (13\% vs 5\%), that there was limited overlap between VAE and traditionally defined VAP ( 8 of 20 VAPs met VAE criteria, 8 of 54 VAEs met VAP criteria), and that the attributable mortality of VAEs was much higher than traditionally defined VAP. This was particularly true of the infectious subset of VAEs, known as infection-related ventilator-associated complications, where the cause-specific hazard ratio for death was 2.42 (95\% CI 1.39-4.20). By contrast, the cause-specific hazard ratio for death for traditionally defined VAP was low and not statistically significant at 1.08 (95\% CI $0.44-$ 2.66).

The author has disclosed a relationship with the Centers for Disease Control and Prevention.

Correspondence: Michael Klompas MD MPH, Department of Population Medicine, 401 Park Drive, Suite 401 East, Boston, MA 02215. E-mail: mklompas@bwh.harvard.edu.

DOI: $10.4187 /$ respcare 05890
One of the strengths of the study by Kobayashi et $\mathrm{al}^{4}$ is that they used rigorous statistical methods to measure attributable mortality. They adjusted for both time-dependent confounding (the notion that increasing time on a

See the Original Study on Page 1379

ventilator is both a risk factor for VAE and a risk factor for poor outcomes) and multiple indicators of severity of illness (including age, sex, height, weight, ICU type, comorbidities, and Acute Physiology and Chronic Health Evaluation II [APACHE II] scores). The authors limited their investigation to subjects ventilated for $\geq 4 \mathrm{~d}$ based on the rationale that patients can only meet VAE criteria after a minimum of $4 \mathrm{~d}$ of mechanical ventilation. If anything, this decision makes their results more conservative. Imagine, if you will, a patient on track to be extubated on ventilator day 3 who develops a potentially preventable complication, such as aspiration, volume overload, or ARDS, on ventilator day 3 . The event will probably trigger a VAE and will almost certainly extend the patient's time receiving mechanical ventilation. In assessing the attributable mortality of this VAE, it would seem appropriate to compare this patient's outcome with that of a similar patient who was also on track to be extubated on ventilator day 3 but did not develop a complication. The decision by Kobayashi et $\mathrm{al}^{4}$ to limit the study population to subjects ventilated $\geq 4 \mathrm{~d}$ focuses the control population upon a sicker set of subjects and thus conservatively estimates the attributable mortality of VAE.

The limited overlap between VAE and traditionally defined VAP mirrors prior investigations. . $^{5-9}$ The fact that many VAEs do not qualify as VAPs is not surprising, given the CDC's explicit intent to use VAE surveillance to broaden the focus of quality surveillance beyond pneumonia alone. The fact that many VAPs do not qualify as VAEs is less intuitive. On reflection, however, it should be apparent that a VAP that does not qualify as a VAE is one in which ventilator settings were stable. In other words, VAE criteria impose a threshold effect that limits detection to patients with severe disease. Clinically suspected VAPs that do not require more ventilator support are presumably a mix of milder pneumonias and misdiagnoses. ${ }^{10,11}$ These are arguably less critical events, given that they have lower mortality rates compared with VAPs that re- 


\section{EDITORIALS}

quire higher ventilator settings, and they have similar outcomes when treated with very short courses of antibiotic (1-3 d) compared with longer courses. ${ }^{11-13}$

The affirmation by Kobayashi et $\mathrm{al}^{4}$ of the high frequency and high attributable mortality of VAEs begs the question of what can be done to prevent these events. There are many reasons to believe that simply continuing business as usual with our current ventilator bundles alone will not be adequate. First, as Kobayashi et $\mathrm{al}^{4}$ confirmed, there is limited overlap between VAE and VAP. Interventions that target VAP alone will only have a limited effect on preventing VAEs, since many VAEs are due to conditions other than VAP. Second, it is becoming increasingly apparent that we may have an exaggerated sense of the success of our current ventilator bundles. Many institutions reported lower VAP rates after implementing ventilator bundles, but these results are difficult to interpret, given the subjectivity of traditional VAP definitions. ${ }^{14}$ Lower VAP rates may indicate less disease, stricter application of subjective surveillance criteria, or both. A recent audit conducted by the Centers for Medicare and Medicaid Services found that VAP rates were essentially stable between 2005 and 2013. ${ }^{15}$ Finally, evidence is mounting that some commonly utilized ventilator bundle components may in fact be harmful for some patients. Oral care with chlorhexidine does not clearly lower VAP rates and may increase mortality rates. ${ }^{16-19}$ Data are mixed, but some studies suggest stress that stress ulcer prophylaxis may increase pneumonia and Clostridium difficile rates. ${ }^{19-21}$

The arrival of VAE criteria has created an opportunity for hospitals to reexamine and reimagine their approach to preventing complications and improving outcomes for mechanically ventilated patients. Care factors identified thus far that increase VAE risk include deep and sustained sedation, sedation with benzodiazepines and propofol, positive fluid balance, packed red blood cell transfusions, and high-tidal volume ventilation.6,19,22-25 Conceptually, the practices most likely to prevent VAEs then are those that help patients avoid intubation, minimize the duration of mechanical ventilation, and/or prevent the conditions that most commonly trigger VAEs (pneumonia, volume overload, ARDS, and atelectasis). ${ }^{26}$

Best practices to avoid intubation include using highflow nasal oxygen for hypoxemic respiratory failure and/or noninvasive ventilation for hypercapnic respiratory failure when safe to do so. ${ }^{27,28}$ Strategies to decrease the duration of mechanical ventilation include minimizing sedation, performing daily coordinated spontaneous awakening and breathing trials, and perhaps early mobility. ${ }^{29-31}$ Strategies to prevent pneumonia, volume overload, ARDS, and atelectasis include head-of-bed elevation, conservative fluid management, conservative blood transfusion thresholds, low tidal volume ventilation, and early mobility. ${ }^{32-35}$ These interventions are not controversial. They are consistent with emerging best practice bundles in critical care, including the ABCDEF bundle, the Surviving Sepsis Campaign, and the Society for Healthcare Epidemiology of America's recommendations to prevent VAP. ${ }^{36-38}$

A growing number of studies affirm that implementing and optimizing these practices can lower VAE rates and improve patient outcomes. The evidence is most robust thus far for daily spontaneous awakening trials, daily spontaneous breathing trials, coordination of spontaneous awakening and breathing trials, and conservative fluid management. $6,39-41$ No study to date, however, has assessed the impact of a fully optimized VAE prevention bundle that includes all of the measures listed above. The high attributable mortality of VAEs paired with the promising results of VAE prevention studies thus far suggest that a fully optimized VAE bundle could be very beneficial for patents. Our mandate for the next 5 years is clear.

Michael Klompas MD MPH Department of Population Medicine Harvard Medical School and Harvard Pilgrim Health Care Institute Department of Medicine Brigham and Women's Hospital Boston, Massachusetts

\section{REFERENCES}

1. Klompas M, Platt R. Ventilator-associated pneumonia-the wrong quality measure for benchmarking. Ann Intern Med 2007;147(11): 803-805.

2. Magill SS, Klompas M, Balk R, Burns SM, Deutschman CS, Diekema $\mathrm{D}$, et al. Developing a new, national approach to surveillance for ventilator-associated events. Crit Care Med 2013;41(11):2467-2475.

3. Magill SS, Li Q, Gross C, Dudeck M, Allen-Bridson K, Edwards JR. Incidence and characteristics of ventilator-associated events reported to the National Healthcare Safety Network in 2014. Crit Care Med 2016;44(12):2154-2162.

4. Kobayashi H, Uchino S, Takinami M, Uezono S. The impact of ventilator-associated events in critically ill subjects with prolonged mechanical ventilation. Respir Care 2017;62(11):1379-1386.

5. Klompas M, Khan Y, Kleinman K, Evans RS, Lloyd JF, Stevenson $\mathrm{K}$, et al. Multicenter evaluation of a novel surveillance paradigm for complications of mechanical ventilation. PLoS One 2011;6(3): e18062.

6. Muscedere J, Sinuff T, Heyland DK, Dodek PM, Keenan SP, Wood $\mathrm{G}$, et al. The clinical impact and preventability of ventilator-associated conditions in critically ill mechanically ventilated patients. Chest 2013;144(5):1453-1460.

7. Klein Klouwenberg PM, van Mourik MS, Ong DS, Horn J, Schultz MJ, Cremer OL, et al. Electronic implementation of a novel surveillance paradigm for ventilator-associated events: feasibility and validation. Am J Respir Crit Care Med 2014;189(8):947-955.

8. Chang HC, Kung SC, Wang CM, Liu WL. Discordance between novel and traditional surveillance paradigm of ventilator-associated pneumonia. Infect Control Hosp Epidemiol 2014;35(9):1195-1196.

9. Bouadma L, Sonneville R, Garrouste-Orgeas M, Darmon M, Souweine B, Voiriot G, et al. Ventilator-associated events: prevalence, 


\section{EDITORIALS}

outcome, and relationship with ventilator-associated pneumonia. Crit Care Med 2015;43(9):1798-1806.

10. Nussenblatt V, Avdic E, Berenholtz S, Daugherty E, Hadhazy E, Lipsett PA, et al. Ventilator-associated pneumonia: overdiagnosis and treatment are common in medical and surgical intensive care units. Infect Control Hosp Epidemiol 2014;35(3):278-284.

11. Esperatti M, Ferrer M, Giunta V, Ranzani OT, Saucedo LM, Li Bassi $\mathrm{G}$, et al. Validation of predictors of adverse outcomes in hospitalacquired pneumonia in the ICU. Crit Care Med 2013;41(9):21512161.

12. Klompas M, Magill S, Robicsek A, Strymish JM, Kleinman K, Evans RS, et al. Objective surveillance definitions for ventilator-associated pneumonia. Crit Care Med 2012;40(12):3154-3161.

13. Klompas M, Li L, Menchaca JT, Gruber S, Centers for Disease Control and Prevention Epicenters Program. Ultra-short-course antibiotics for patients with suspected ventilator-associated pneumonia but minimal and stable ventilator settings. Clin Infect Dis 2017; 64(7):870-876.

14. Klompas M. Eight initiatives that misleadingly lower ventilator-associated pneumonia rates. Am J Infect Control 2012;40(5):408-410.

15. Metersky ML, Wang Y, Klompas M, Eckenrode S, Bakullari A, Eldridge N. Trend in ventilator-associated pneumonia rates between 2005 and 2013 JAMA 2016;316(22):2427-2429.

16. Klompas M, Speck K, Howell MD, Greene LR, Berenholtz SM. Reappraisal of routine oral care with chlorhexidine gluconate for patients receiving mechanical ventilation: systematic review and meta-analysis. JAMA Intern Med 2014;174(5):751-761.

17. Price R, MacLennan G, Glen J. Selective digestive or oropharyngeal decontamination and topical oropharyngeal chlorhexidine for prevention of death in general intensive care: systematic review and network meta-analysis. BMJ 2014;348:g2197.

18. Klompas M. Oropharyngeal decontamination with antiseptics to prevent ventilator-associated pneumonia: rethinking the benefits of chlorhexidine. Semin Respir Crit Care Med 2017;38(3):381-390.

19. Klompas M, Li L, Kleinman K, Szumita PM, Massaro AF. Associations between ventilator bundle components and outcomes. JAMA Intern Med 2016;176(9):1277-1283.

20. Sasabuchi Y, Matsui H, Lefor AK, Fushimi K, Yasunaga H. Risks and benefits of stress ulcer prophylaxis for patients with severe sepsis. Crit Care Med 2016;44(7):e464-e469.

21. Alhazzani W, Guyatt G, Alshahrani M, Deane AM, Marshall JC, Hall R, et al. Withholding pantoprazole for stress ulcer prophylaxis in critically ill patients: a pilot randomized clinical trial and metaanalysis. Crit Care Med 2017;45(7):1121-1129.

22. Lewis SC, Li L, Murphy MV, Klompas M. Risk factors for ventilator-associated events: a case-control multivariable analysis. Crit Care Med 2014;42(8):1839-1848.

23. Cocoros NM, Priebe G, Gray JE, Toltzis P, Larsen GY, Logan LK, et al. Factors associated with pediatric ventilator-associated conditions in six U.S. hospitals: a nested case-control study. Pediatr Crit Care Med 2017. doi: 10.1097/PCC.0000000000001328.

24. Ogbu OC, Martin GS, Sevransky JE, Murphy DJ. High tidal volumes are independently associated with development of a ventilator-associated condition in the ICU. Am J Respir Crit Care Med 2015;191: A3117.

25. Klompas M, Li L, Szumita P, Kleinman K, Murphy MV, CDC Prevention Epicenters Program. Associations between different sedatives and ventilator-associated events, length of stay, and mortality in patients who were mechanically ventilated. Chest 2016;149(6): 1373-1379.

26. Klompas M. Potential strategies to prevent ventilator-associated events. Am J Respir Crit Care Med 2015;192(12):1420-1430.
27. Frat JP, Thille AW, Mercat A, Girault C, Ragot S, Perbet S, et al. High-flow oxygen through nasal cannula in acute hypoxemic respiratory failure. N Engl J Med 2015;372(23):2185-2196.

28. Osadnik CR, Tee VS, Carson-Chahhoud KV, Picot J, Wedzicha JA, Smith BJ. Non-invasive ventilation for the management of acute hypercapnic respiratory failure due to exacerbation of chronic obstructive pulmonary disease. Cochrane Database Syst Rev 2017;(7): CD004104.

29. Strøm T, Martinussen T, Toft P. A protocol of no sedation for critically ill patients receiving mechanical ventilation: a randomised trial. Lancet 2010;375(9713):475-480.

30. Girard TD, Kress JP, Fuchs BD, Thomason JW, Schweickert WD, Pun BT, et al. Efficacy and safety of a paired sedation and ventilator weaning protocol for mechanically ventilated patients in intensive care (Awakening and Breathing Controlled trial): a randomised controlled trial. Lancet 2008;371(9607):126-134.

31. Schweickert WD, Pohlman MC, Pohlman AS, Nigos C, Pawlik AJ, Esbrook CL, et al. Early physical and occupational therapy in mechanically ventilated, critically ill patients: a randomised controlled trial. Lancet 2009;373(9678): 1874-1882.

32. Wang L, Li X, Yang Z, Tang X, Yuan Q, Deng L, et al. Semirecumbent position versus supine position for the prevention of ventilator-associated pneumonia in adults requiring mechanical ventilation. Cochrane Database Syst Rev 2016;(1):CD009946.

33. Mekontso Dessap A, Roche-Campo F, Kouatchet A, Tomicic V, Beduneau G, Sonneville R, et al. Natriuretic peptide-driven fluid management during ventilator weaning: a randomized controlled trial. Am J Respir Crit Care Med 2012;186(12):1256-1263.

34. Hébert PC, Wells G, Blajchman MA, Marshall J, Martin C, Pagliarello $\mathrm{G}$, et al. A multicenter, randomized, controlled clinical trial of transfusion requirements in critical care: transfusion requirements in critical care investigators, Canadian Critical Care Trials Group. NEngl J Med 1999;340(6):409-417.

35. Yadav H, Thompson BT, Gajic O. Fifty years of research in ARDS: is acute respiratory distress syndrome a preventable disease? Am J Respir Crit Care Med 2017;195(6):725-736.

36. Barnes-Daly MA, Phillips G, Ely EW. Improving hospital survival and reducing brain dysfunction at seven California community hospitals: implementing PAD guidelines via the ABCDEF bundle in 6,064 patients. Crit Care Med 2017;45(2):171-178.

37. Rhodes A, Evans LE, Alhazzani W, Levy MM, Antonelli M, Ferrer $\mathrm{R}$, et al. Surviving Sepsis Campaign: international guidelines for management of sepsis and septic shock: 2016. Crit Care Med 2017; 45(3):486-552.

38. Klompas M, Branson R, Eichenwald EC, Greene LR, Howell MD, Lee G, et al. Strategies to prevent ventilator-associated pneumonia in acute care hospitals: 2014 update. Infect Control Hosp Epidemiol 2014;35(8):915-936.

39. Klompas M, Anderson D, Trick W, Babcock H, Kerlin MP, Li L, et al. The preventability of ventilator-associated events: the CDC Prevention Epicenters Wake Up and Breathe Collaborative. Am J Respir Crit Care Med 2015;191(3):292-301.

40. Mekontso Dessap A, Katsahian S, Roche-Campo F, Varet H, Kouatchet A, Tomicic V, et al. Ventilator-associated pneumonia during weaning from mechanical ventilation: role of fluid management. Chest 2014;146(1):58-65.

41. Rawat N, Yang T, Ali KJ, Catanzaro M, Cohen MD, Farley DO, et al. Two-state collaborative study of a multifaceted intervention to decrease ventilator-associated events. Crit Care Med 2017;45(7): 1208-1215. 